\title{
Habitat engineering by decadal-scale bioturbation around shipwrecks on the Great Barrier Reef mid-shelf
}

\author{
Thomas C. Stieglitz ${ }^{1,2,3,4, *}$ \\ 19IMS@JCU, Townsville, Queensland 4811, Australia \\ ${ }^{2}$ School of Engineering \& Physical Sciences, James Cook University, Townsville, Queensland 4811, Australia \\ ${ }^{3}$ Australian Institute of Marine Science, Townsville, Queensland 4810, Australia \\ ${ }^{4}$ Present address: CNRS — LEMAR (Laboratoire des sciences de l'environnement marin) UMR 6539, \\ Institut Universitaire Européen de la Mer, 29280 Plouzané, France
}

\begin{abstract}
Conspicuous, systematic patterns of holes in soft sediment around wreck sites on the Great Barrier Reef mid-shelf are documented. Multibeam bathymetry data show concentric 'halos of holes' extending hundreds of meters around the wrecks. These halos at 5 wreck sites between 16 and $111 \mathrm{yr}$ old consist of hundreds of tightly spaced depressions with diameters of up to $10 \mathrm{~m}$. Seafloor imagery clearly indicates a biogenic origin of the holes. The halos of the 2 youngest wrecks $(<25$ yr) have fewer holes than older wrecks, suggesting a relationship between wreck age and excavation activity. Conversely, the size of a wreck does not appear to control the sediment turnover activity. Holes are comparatively long-lived, and some of them are actively maintained by bioturbation activity. The spatial distribution of holes is consistent with resource depletion by a central-place forager, albeit on yearly to decadal time scales. Tow-camera data show that some holes support diverse sessile faunal assemblages of sponges, soft corals, and hard corals in an otherwise flat seafloor devoid of sessile fauna. The (to date unknown) bioturbator(s) are thus allogenic habitat engineers. The systematic occurrence of halos around wrecks suggests that 'the ecosystem wreck' extends beyond the spatial confines of the hull of a wreck to the seafloor, by a distance 10-fold greater than the size of a wreck itself. This has implications for the evaluation of ecological effects of artificial reefs such as wrecks and offshore wind farms on decadal time scales.
\end{abstract}

KEY WORDS: Bioturbation - Shipwreck · Artificial reef - Holes · Ecosystem engineering Soft-sediment habitat · Multibeam sonar · Great Barrier Reef · Yongala

Resale or republication not permitted without written consent of the publisher

\section{INTRODUCTION}

The Great Barrier Reef (GBR) Marine Park, a UNESCO World Heritage Area, hosts a diverse range of benthic habitats, extending from shallow coastal environments to extensive coral reefs on the outer shelf along the $2000 \mathrm{~km}$ long GBR coastline. GBR reef and seafloor habitats are currently managed in a zoning system, ranging from no-take to multipleuse zones (www.gbrmpa.gov.au/__data/assets/pdf_
file/0015/3390/GBRMPA-zoning-plan-2003.pdf). The mid-shelf between coast and reef is up to $50 \mathrm{~km}$ wide and consists predominantly of sedimentary habitats interspersed with comparatively small shoal (hard) ground habitats (e.g. Pitcher et al. 2002). These locations, although sparsely distributed, provide important habitats for diverse sessile and mobile species, are important contributors to fisheries productivity, and act as 'stepping stones' for mobile species, providing connectivity between nearshore and offshore 
habitats (Cappo \& Kelley 2001). Nevertheless, habitats on the GBR mid-shelf have traditionally received much less scientific attention than their reef counterparts. In recent years, however, an increasing effort has been directed at understanding their diversity and role in supporting benthic biodiversity, partially as a result of a shift in focus of commercial and recreational line fisheries towards these mid-shelf habitats away from the reef on the outer shelf, resulting from a new protection (zoning) plan of the GBR introduced in 2005 (Cappo et al. 2012). This presented a major challenge for reef and fisheries management, because up until then almost no information on the distribution and value of these habitats had been available (Cappo et al. 2012).

As part of a pilot program on multibeam bathymetry mapping of such mid-shelf habitats, between 2004 and 2007 several wreck sites were investigated. These artificial reefs, although not intentionally installed, contribute considerably to the economical services provided by the GBR, either through recreational and commercial fishing or as recreational dive sites. Indeed, one of the investigated wrecks, the SS 'Yongala,' is among Australia's most famous dive sites, attracting thousands of recreational divers each year. One of the prime reasons for the popularity of the 'Yongala' and other wrecks elsewhere in the world is the extraordinary diversity in sessile and mobile species rivaling those of natural coral reef sites (e.g. Malcolm et al. 1999).

Whilst there is an increasing interest in using and deploying artificial reefs for management or harvesting of marine resources, e.g. for fisheries but also offshore wind farms, little is known about the effects of artificial reefs on the morphology and ecology of the surrounding seafloor. The multibeam bathymetry surveys document substantial, systematic excavations in the form of halos of holes around all investigated shipwrecks unknown to divers or fishermen, which are reported herein. Multibeam bathymetry and tow-camera data clearly indicate a biogenic origin of the holes, but despite a considerable coverage by camera tows and diver observations, the species responsible for the excavations remain(s) unknown to date. In other settings, the holes most similar in morphology to those observed at the wrecks are inhabited by red grouper in the Gulf of Mexico; however, they are not arranged in halos around structural habitat (Scanlon et al. 2005, Coleman et al. 2010, Wall et al. 2011).
An understanding of the processes structuring softsediment communities requires the identification of the appropriate spatial and temporal scale of the structuring activity (Thrush 1999, Hastings et al. 2007, Fonseca et al. 2008). The observations of halos of holes at wrecks of different age and size provide a rare opportunity to investigate the temporal development of decadal-scale processes. Notwithstanding our lack of understanding of the origin of the holes, the observations at the different wrecks allow us to draw some conclusions on spatial and temporal scales of the creation and maintenance of these excavations.

\section{MATERIALS AND METHODS}

\section{Study sites}

The gently sloping mid-shelf in the central GBR region extends from the $20 \mathrm{~m}$ isobath $\sim 10 \mathrm{~km}$ off the coastline to a depth of 50 to $60 \mathrm{~m}$ at the inner edge of the barrier reef, with few prominent bathymetric features (Fig. 1). Mid-shelf surface sediments are predominantly of carbonate origin and are similar at all study sites (Orpin et al. 1999, Pitcher et al. 2002). Between latitudes 18.0 and $19.3^{\circ} \mathrm{S}$, we investigated 5 wreck sites (Fig. 1). The $110 \mathrm{~m}$ long passenger vessel

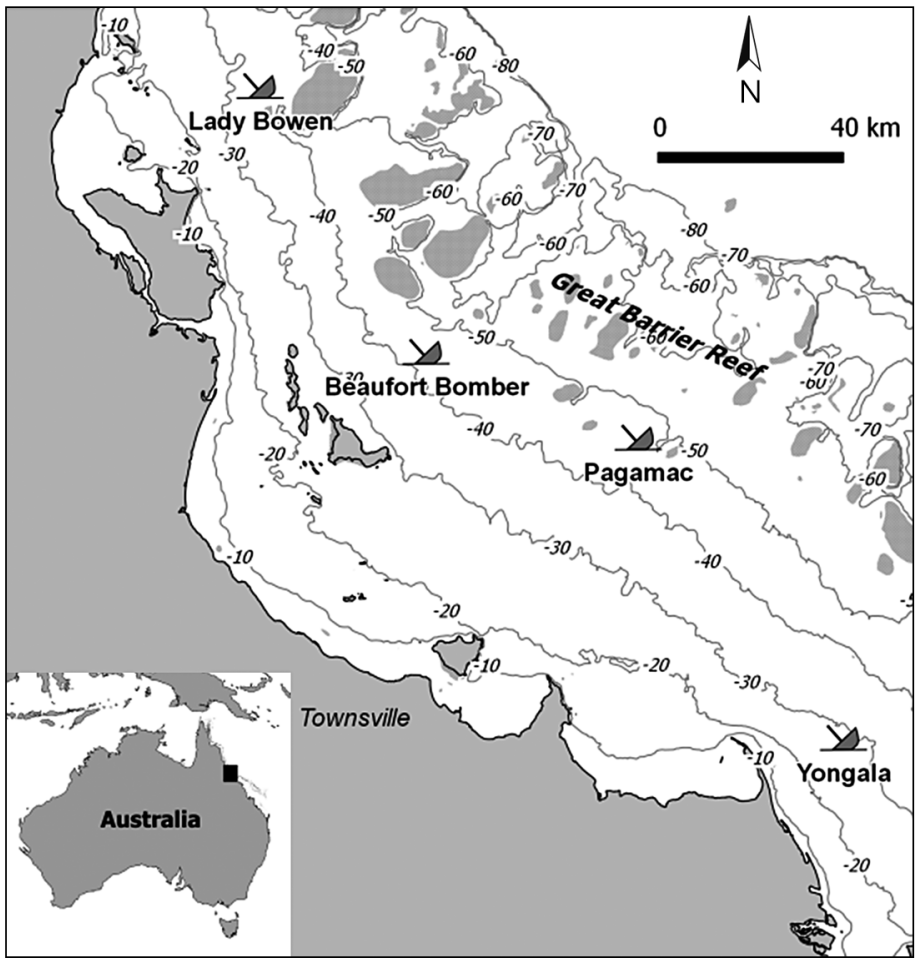

Fig. 1. Wreck locations in the central Great Barrier Reef, Australia 
'Yongala' sank on 21 March 1911 during a cyclone $\sim 25 \mathrm{~km}$ off the coast. Despite regular dive tourism, the wreck site and the adjacent seafloor are, in ecological terms, in quasi-pristine conditions. Near the 'Yongala' lies the 'Pure Pleasure,' an $11 \mathrm{~m}$ dive vessel which sank on 16 April 1994. The location of this wreck is confidential and thus not indicated on the presented maps. Farther north and closer to the barrier reef, the $18 \mathrm{~m}$ long trawler 'Pagamac' was wrecked on 15 November 1983. In 1942, a 'Beaufort Bomber' plane sank off the Palm Group of Islands, of which today only the cockpit and a small amount of fuselage protrudes from the seafloor ( $6 \mathrm{~m}$ footprint in multibeam bathymetry data). The $65 \mathrm{~m}$ long schooner 'Lady Bowen' sank on 18 August 1894 after colliding with a reef. The wrecks of the 'Yongala' and the 'Lady Bowen' are protected by Maritime Heritage legislation (Australian Historic Shipwrecks Act of 1976) which restricts dive activities and anchoring near the wreck sites, and are included in the Australian Government's inventory of historically significant shipwrecks (www.environment.gov.au/heritage/ shipwrecks). In addition, the 'Yongala' lies in a Marine National Park ('Green Zone', no-take zone). Average water depth of the study sites ranges between 28 and $42 \mathrm{~m}$.

\section{Bathymetry mapping}

The wrecks and the surrounding seafloor were mapped with a pole-mounted Reson Seabat 8101 multibeam echosounder between November 2004 and July 2007. The 'Yongala' was mapped twice, in November 2004 and July 2007. The Seabat 8101 operates at $240 \mathrm{kHz}$ and has 101 beams with an along-track and across-track beam width of $1.5^{\circ}$. In $20 \mathrm{~m}$ water depth, nominal nadir footprint size is $0.5 \mathrm{~m}$, and vertical resolution is better than $5 \mathrm{~cm}$. Vessel track, heading, and motion were recorded with a differential GPS receiver, the vessel's gyrocompass, and a TSS DMS dynamic motion sensor mounted at the center of gravity of the vessel, respectively. Multibeam data were time-stamped with a 1 pulse $\mathrm{s}^{-1}$ signal from the GPS, eliminating time delays (latency) between sensors. Sonar ranges were converted to depth by integrating the range, GPS, heading, and motion data whereby the acoustic data were corrected for refraction using sound velocity profiles representative for ocean conditions at the time of data collection, and tidal water level variation was corrected to prediction datum using tidal prediction data by the Australian Hydrographic Office. Raw soundings were reduced to a bathymetry grid with a horizontal resolution of $0.5 \mathrm{~m}$, whereby data were weighted by beam number giving preference to inner beam data. Data collected with the outer 15 beams on both sides of the vessel were excluded from the analysis in order to limit distortion of observed holes due to a large footprint and low acoustic incidence angles. Small artifacts due to imperfect correction of vessel motion are present in the resulting bathymetry data.

\section{Halo characterization}

Locations of individual holes were extracted from the multibeam bathymetry data by calculating local minima in the bathymetric grid. The depth of an individual hole can be difficult to calculate where holes are located close to each other and a seafloor surface around the holes is difficult to determine, from which the hole depth can be measured. The slope of the sidewalls is independent of this surface, and therefore the holes were classified based on the slope of their rim as calculated from the multibeam data. A hole was classified as 'shallow' ( $\geq 50 \%$ of rim slope between $2^{\circ}$ and $15^{\circ}$ ) or as 'deep' (>50\% of rim slope $>15^{\circ}$ ). Isolated shallow holes that were missed by this categorization or 'false detects' (e.g. due to double detection or motion artifact) were edited manually based on visual inspection of the bathymetry data. The distance of each hole to the center point of the wreck and to its closest neighbor (hole pairs) were calculated to characterize the spatial properties of halos and to assess variability between study sites.

\section{Benthic habitat characterization}

In September 2008, 1305 oblique-angle photographs of the seafloor at the 'Yongala' were taken with an automatically triggering still-camera suspended from a float, which was drifting slowly with the prevailing currents. The camera was suspended ca. $1.5 \mathrm{~m}$ above the seafloor, and photographs were geo-referenced using position data recorded with a handheld GPS mounted on the drifting float. Layback of the camera to GPS location is negligible for this experimental setup.

Sessile epibenthic assemblages were classified at the community level into 5 categories: 'bare,' 'marine plants,' 'rubble,' 'isolate,' and 'garden.' The category 'bare' was applied where no (or almost no) macroscopic growth was observed. 'Marine plants' include 
assemblages dominated by algae (predominantly Caulerpa, Halimeda, and Udotea spp.) and seagrass (predominantly Halophila and Halodule spp.), representing a common assemblage on the 'flat' interreefal seafloor of the GBR (Pitcher et al. 2002). 'Rubble' consists of either loose rubble in the centi- to decimeter size range, but also meter-scale patches of rubble covered in crustose coralline or other algae. An 'isolate' is a singular individual or small group of individual animals (or colonies) of sponges or soft corals (including sea whip and gorgonian species). Finally, an inter-reefal 'garden' consists of a dense and diverse assemblage of marine plants, sponges, soft corals, and the occasional hard coral (mostly Acropora spp.) (Cappo \& Kelley 2001). Mobile species (e.g. small fish, sea cucumbers, sea stars, sea snakes) were present on rare occasions, but their distribution does not contribute in a meaningful way to the interpretation of the habitats and was thus not included. This classification scheme, though simple, allows the assessment of the relationship between sessile biota and the seabed structure resulting from bioturbation activity. For this purpose, for each re- corded image, the closest center point of a hole was determined from the multibeam data. If a centre point was present within a range of $10 \mathrm{~m}$, this centre point was assigned to the image. Where no hole was present within this distance, 'flat seafloor' was assigned.

\section{RESULTS}

\section{Spatial distribution of holes}

The multibeam bathymetry data clearly delineated closely packed fields of holes distributed in halos around the wreck sites (Fig. 2). Individual holes were up to $10 \mathrm{~m}$ in diameter. Hole depth ranged from a few decimeters up to $1.7 \mathrm{~m}$ (Fig. 3). The mean (central) location of all holes associated with an individual wreck was located within $<35 \mathrm{~m}$ distance from the wreck (a distance smaller than the length of the respective wreck; Fig. 4). Elsewhere, the seafloor was flat, with no macroscopic structure other than the wreck.

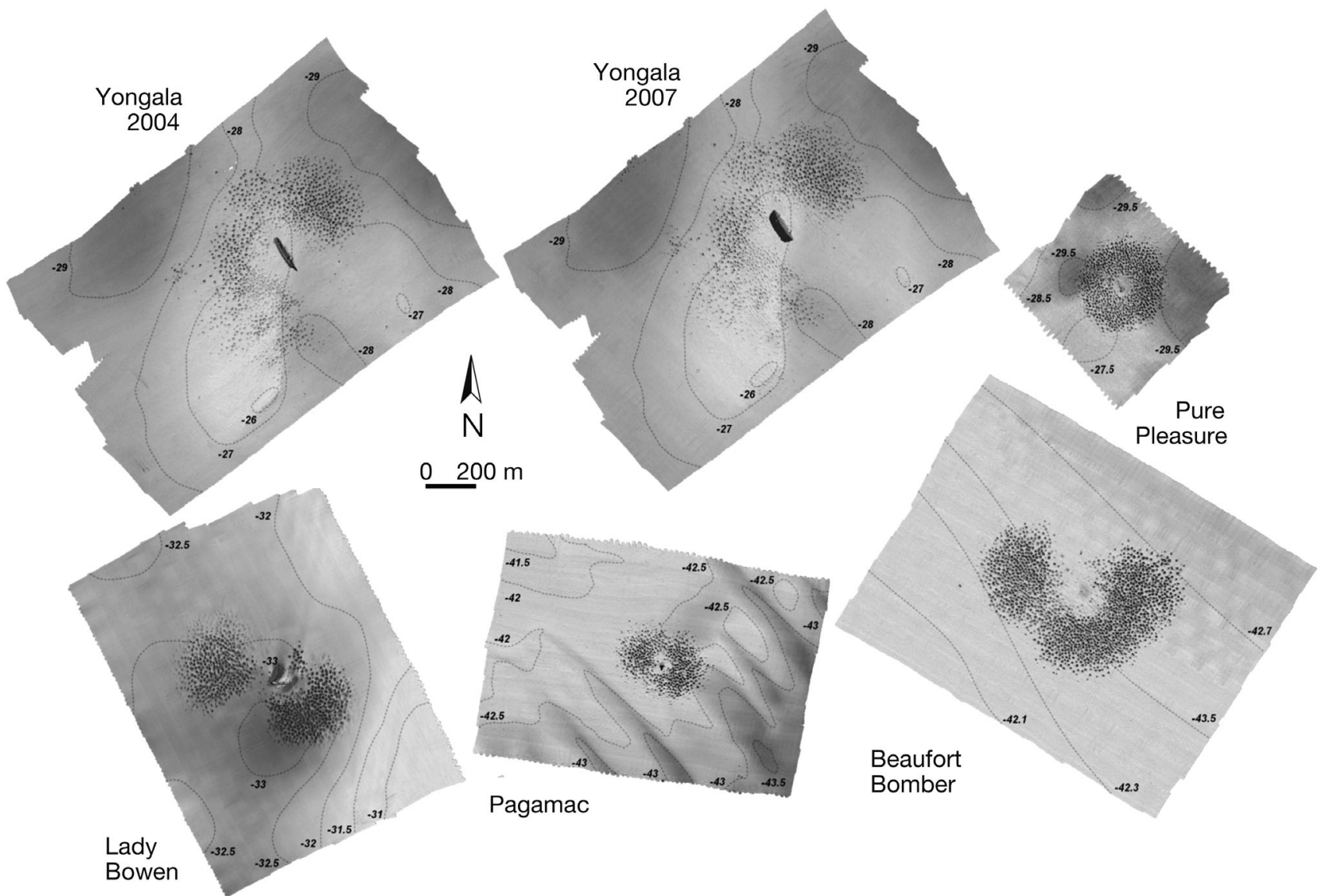

Fig. 2. Sun-shaded multibeam bathymetry of wreck sites. Grey scale indicates depth (depth contours in m). All sites are presented at the same scale for comparison. North is up on all maps 


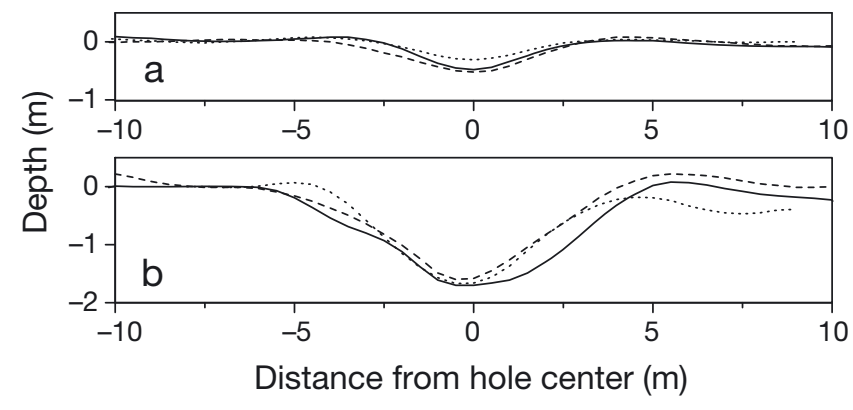

Fig. 3. Typical relative depth profiles of (a) 3 shallow and (b) 3 deep holes

Halos were characterized by a narrow 'blank' zone around the wreck with few holes, and a maximum extension of $\sim 600 \mathrm{~m}$ from the wreck. Within a range of $600 \mathrm{~m}$ from each wreck, the hole density was between 440 and $1300 \mathrm{~km}^{-2}$ (cf. Table 1). At the 'Yongala,' the 'Beaufort Bomber,' and the 'Lady Bowen,' the majority of the holes $(85,92$, and $86 \%$, respectively) were distributed in a range between 100 and $350 \mathrm{~m}$ from the center of the wreck, whereas at the 'Pure Pleasure' and 'Pagamac,' 84 and $81 \%$, respectively, were scattered between 50 and $150 \mathrm{~m}$ from the wreck (Fig. 5a). Holes were found across the full depth range of each survey area (Fig. 4).

Shallow holes were found at inner and outer edges of the halos, and occupied parts of the main halo at the 'Yongala,' the 'Pagamac,' and the 'Beaufort Bomber' (Fig. 4). Within the halo, hole-to-hole distances were frequently of the same order as individual hole diameter, with a great majority of hole-tohole distances in the 5 to $15 \mathrm{~m}$ range at all wrecks (Fig. 5b).

At the 'Pure Pleasure' and the 'Pagamac,' the halos formed a closed $360^{\circ}$ circle, whereas a gap was evident in the southeast sector at the 'Yongala,' in the northern sector at the 'Beaufort Bomber,' and north and south of the 'Lady Bowen' (Fig. 4). The blank sector appeared to be associated with major current directions. At the 'Lady Bowen,' for example, visible scours indicated a strong effect of currents on the distribution of holes. Similarly, at the 'Yongala,' a blank zone in the southeast was consistent with the prevailing tidal current in a southeast-northwest direction (IMOS 2010). The reason for this preference for exca-

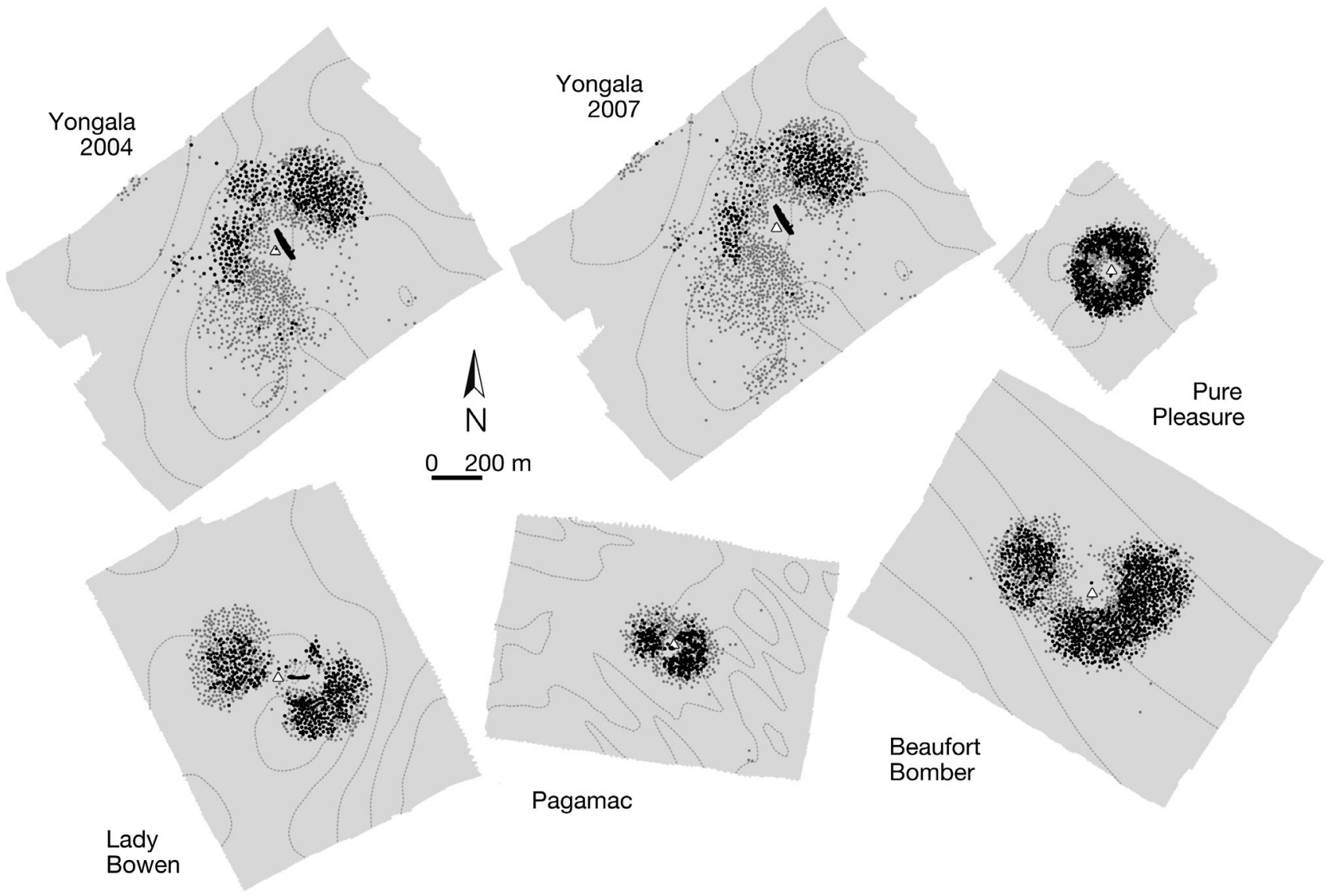

Fig. 4. Classification of halos of holes at wreck sites into deep (black) and shallow (grey) holes. $\Delta$ : mean location of all holes. Depth contours and details as in Fig. 1 
Table 1. Wreck and halo parameters. Date: date on which the vessel sank, depth: average depth of the survey area, height: maximum height of the wreck above the seabed, length: length of the wreck, and age: age between sinking and collection of data. The first 2 rows represent data collected at the 'Yongala' in 2004 and 2007. Counts of holes are also shown

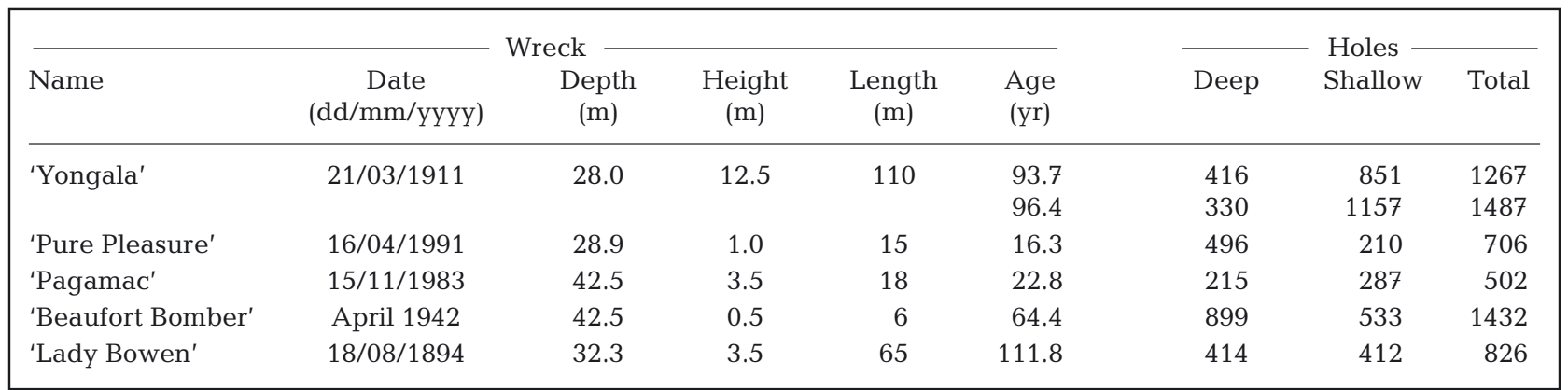
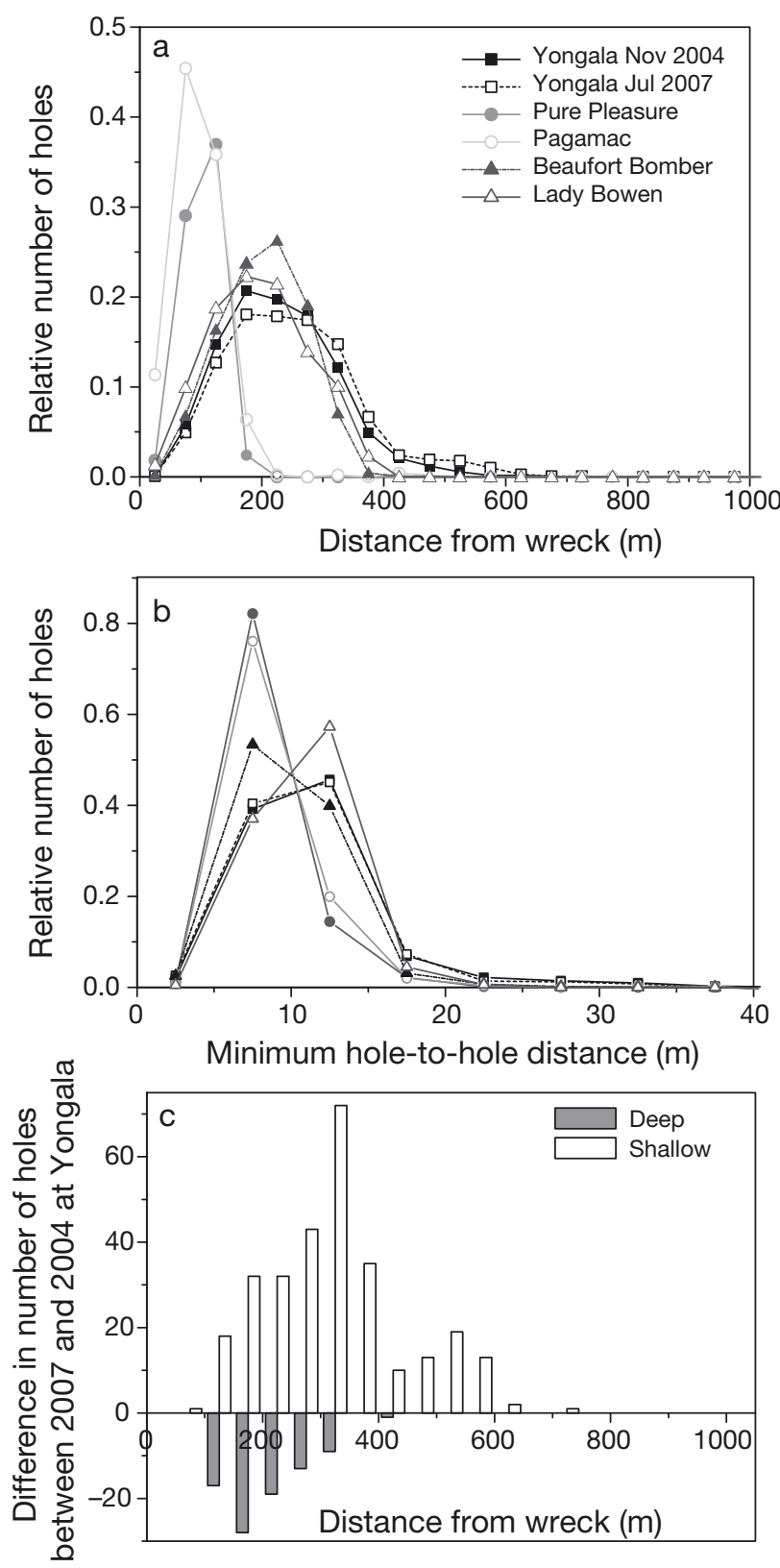

vating perpendicular to the major current direction is likely related to the behavioral process underlying halo formation, but remains unknown to date.

The repeat survey at the 'Yongala' in 2004 and 2007 provided some information on the temporal development of a halo. Overall, an increase in hole number between 2004 and 2007 was observed (Table 1). Changes in hole distribution indicated an outward expansion of the halo (Fig. 5c). Between November 2004 and July 2007, 238 new holes were excavated (5 of which were deep), predominantly at and beyond the outer edge of the 2004 halo, and 31 holes increased in depth (from category 'shallow' to category 'deep') between 2004 and 2007. Conversely, 18 holes present in 2004 were not found in 2007, and 122 deep holes in 2004 were classed as shallow in 2007, indicating an infilling with sediment in parts of the halo. The 2007 survey covered a larger area than in 2004, but for comparison the same area is analyzed and presented here.

\section{Bioturbation features and biological communities}

Seafloor images showed evidence for recent bioturbation activities. Slopes and rims of holes were frequently pitted by what visually appear to be bite marks, and numerous conspicuous mounds were found close to many holes (Fig. 6). Despite a reasonable video observation effort (including limited night-time observations), macroscopic mobile ani-

Fig. 5. Hole distribution within halos: relative number of holes versus (a) distance from wreck in $50 \mathrm{~m}$ intervals and (b) versus hole-to-hole distance in $5 \mathrm{~m}$ intervals; (c) difference in hole class between 2004 and 2007 survey versus distance from the 'Yongala' wreck in $50 \mathrm{~m}$ intervals 
mals (e.g. fish) were not observed to occupy the holes. It appears that the creator(s) of the holes are not permanently using or occupying them.

Flat seafloor surrounding the halo was dominated by marine plants (94\% of images recorded, Figs. 7 \& 8). Bare seafloor, rubble, and isolates were rare, with 2,1 , and $3 \%$ of observations, respectively, and no garden was found outside the halo. Deep holes were most frequently bare (54\% of observations) or filled with rubble or marine plants (23 and $22 \%$, respectively). Few isolates and only 1 garden were found in a deep hole (Fig. 8). Conversely, whilst shallow holes were dominated by marine plants like the surrounding flat seafloor (43\%), isolates and gardens occurred
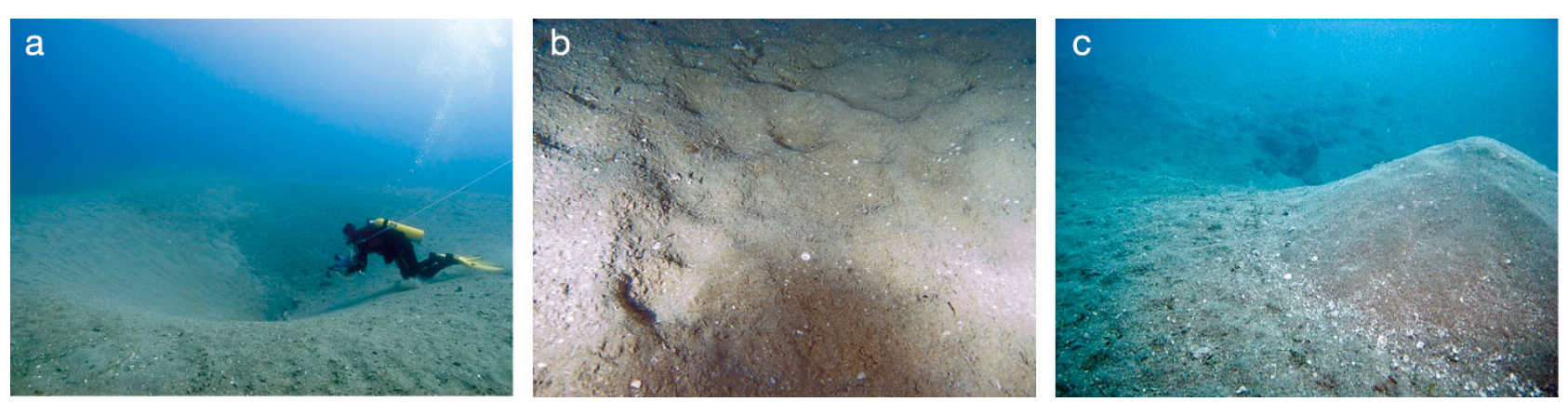

Fig. 6. Bioturbation activity: (a) typical hole with diver for scale; (b) bite marks in side wall (rim) of a hole (marks are estimated to be $10 \mathrm{~cm}$ in $\varnothing$ ); (c) deposition mounds are associated with numerous holes (mound is $\sim \mathrm{m}$ in $\varnothing$ and $50 \mathrm{~cm}$ high)
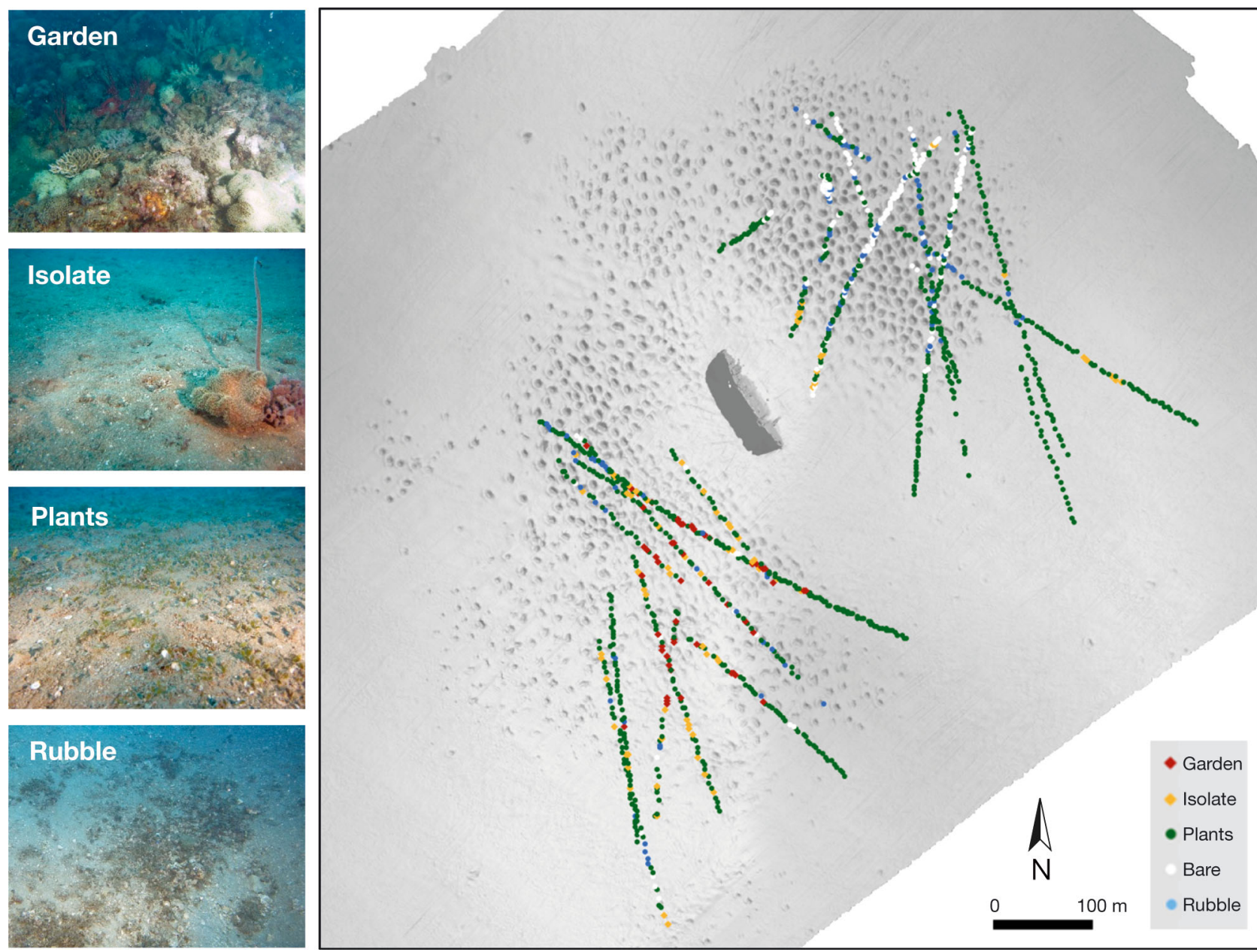

Fig. 7. Classified tow camera data (September 2008) overlaid on multibeam bathymetry of the 'Yongala' wreck collected in July 2007. Images show assemblages typical for the respective category 


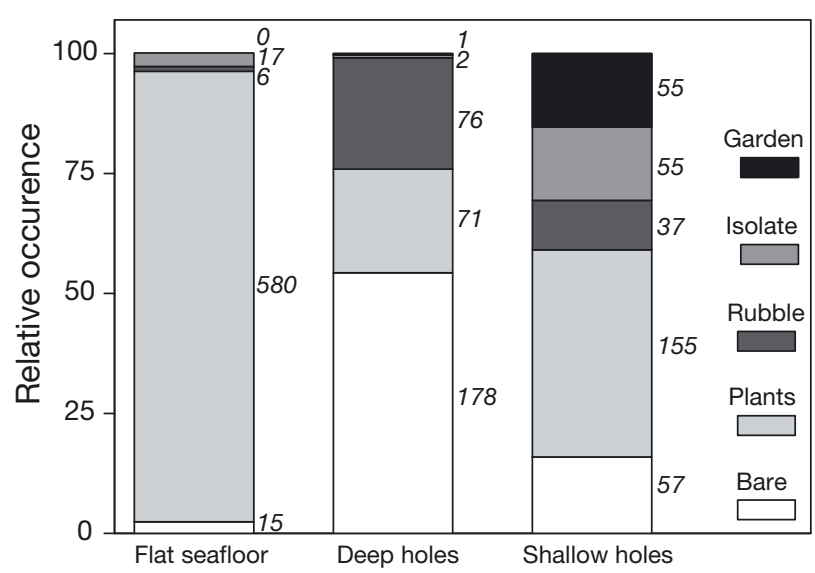

Fig. 8. Relative occurrence of benthic assemblage on flat seafloor and in deep and shallow holes. Italic numbers indicate total number of images per category

comparatively frequently in shallow holes $15 \%$ each of observations made in shallow holes). Overall, sessile fauna in isolates and gardens occurred almost exclusively in shallow holes, mostly southwest of the wreck (Figs. $7 \&$ 8).

\section{DISCUSSION}

\section{Hole morphology}

The holes are most likely of biogenic origin, but the animal(s) responsible for the excavations remain unknown to date. The conspicuous halo-like distribution likely reflects, at least to some degree, the purpose of the building of the hole. It is possible that it represents a pattern in feeding or nesting behavior of demersal species. The bioturbators may range from small fish species to large stingrays (or may not be fishes at all). In addition to decimeter-scale burrows and holes created by polychaetes and crustaceans, numerous meter-scale holes are known to be excavated by fishes. Whale and stingray species are amongst the most prominent species creating substantial feeding scours and pits (e.g. Kvitek \& Oliver 1986, Hines et al. 1997), and tilefish and triggerfish species excavate sites as home territories or nesting sites, respectively (e.g. Fricke 1980, Able et al. 1987). Abiotic processes such as fluid seepage (gas or groundwater seepage, hydrothermal activity) are unlikely to form these halos: fluid seep sites are commonly more complex in the morphology of individual holes (e.g. Hovland \& Judd 1988), and, more importantly, a close geometric relationship with wrecks would not be expected if such processes were at work.
Detailed descriptions of the morphology and distribution of biogenic excavations and holes in shelf environments are rare in the scientific literature. However, individual holes with similar size and morphology to those observed at the wreck sites were recently documented to be excavated by grouper species in a marine reserve in the Gulf of Mexico (Scanlon et al. 2005, Coleman et al. 2010, Wall et al. 2011). Densities of 110 to 140 holes km $\mathrm{km}^{-1}$ of very similar size (up to $10 \mathrm{~m}$ in diameter and up to $1.5 \mathrm{~m}$ deep) were documented with similar multibeam acoustic methods (Wall et al. 2011). Typical hole-to-hole distance was in the 20 to $40 \mathrm{~m}$ range, and acoustic communication was suggested to be a driver of hole spacing, with more than $95 \%$ of all holes within what is considered the range of communication in grouper of $70 \mathrm{~m}$ (Wall et al. 2011). In contrast to these grouper holes, the halos of holes around the wrecks documented here are characterized by significantly smaller hole-to-hole distances and almost 10 times higher density of holes than those observed in the grouper territory. Whilst the shape of individual holes is remarkably similar, shape alone does not necessarily indicate the species or process responsible for it. In a given sediment (here, poorly sorted carbonates like in the Gulf of Mexico), a hole will assume a shape which is determined by center depth and by sediment type (cf. concept of marine slope stability, e.g. Coleman \& Garrison 1977).

Red grouper males excavate and maintain holes as home territories and spawning grounds. Grouper excavate with their mouths and by fanning their fins, and are capable of carrying large amounts of sediment, but Coleman et al. (2010) did not indicate mound building associated with the excavation (as observed here, Fig. 6). Importantly, groupers show high site fidelity; they remain in the same hole for long periods, but do not appear to excavate for feeding purposes (Coleman et al. 2010). Neither grouper nor other fish species were observed to inhabit holes during video and dive observations at the 'Yongala' halo. This indicates that the reason for the excavation is unlikely the creation of habitat that is 'permanently' inhabited like the Gulf of Mexico grouper holes. Night-time observations did not provide any further insight, but were limited to observations of only a few holes for a few hours.

Of the investigated wrecks, information on fish populations currently exists only for the 'Yongala.' Repeat fish population surveys of the wreck found Queensland grouper Epinephelus lanceolatus and other Serranidae, although some species occurred 
only sporadically (Malcolm et al. 1999). Whilst grouper species cannot be excluded as potential excavators, the almost 10-fold density of holes and the lack of residency observed in the holes around the wreck sites suggest that at least the underlying ecological processes (or reason for excavation) differ significantly from those observed in the Gulf of Mexico. Other large species that may contribute to excavation activities are benthic stingrays such as the black-blotched fantail ray Taeniura meyeni, which is frequently sighted at the 'Yongala.' It is also possible that numerous (including smaller) species contribute to the overall excavation activity, with 1 species creating an initial hole which is subsequently maintained by other species.

\section{Temporal variability of halos and time scales of excavation activities}

Despite the absence of a known species responsible for the excavations, the spatial analysis of the systematic distribution of holes provides some useful information on their generation. The observations made at wrecks of different ages as well as repeat surveys at the 'Yongala' allow for a reconstruction of the temporal development of halos.

An outward expansion away from the wreck is evident: (1) The halos around the younger wrecks 'Pure Pleasure' and 'Pagamac' are located closer to the wreck than those of older wrecks (Fig. 5a). (2) At the 'Yongala,' the majority of new holes created between 2004 and 2007 were located at the outer edge of the halo (Fig. 5c). Potential ecological drivers for this outward growing effect are discussed in the subsequent section.

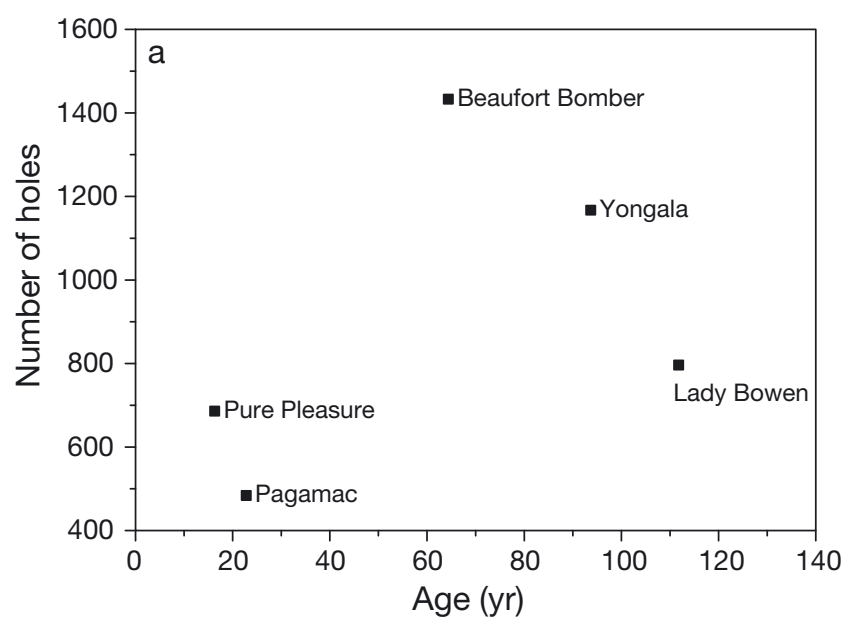

The number of new holes greatly outweighs those that have disappeared between observations in 2004 and 2007 (238 versus 18), together with 31 holes that increased significantly in depth. Assuming the observed excavation rate of ca. 90 new holes $\mathrm{yr}^{-1}$ ( 238 holes in $2.7 \mathrm{yr}$ ) is characteristic for the bioturbation activity and is constant over time, it is apparent that processes must fill in holes over longer periods of time such as wave-, current-, and storm-driven sediment transport. For example, in 2007, the 96 yr old 'Yongala' was surrounded by 1487 holes, which equates to a much lower 'net' (production minus destruction) rate of 15 holes $\mathrm{yr}^{-1}$. An infilling over time is also evident in the reduction in depth of 122 holes between 2004 and 2007. Such average rates must be treated with caution; it is likely that high-energy events such as tropical cyclones have a disproportionate effect on the destruction rate, and thus the rates of excavation and destruction may vary considerably with time.

Results show that these holes are constructed and maintained over time, similar to grouper holes in the Gulf of Mexico (Coleman et al. 2010, Wall et al. 2011). Total excavation activity is accumulative-older wrecks have more holes, persisting over many decades (Fig. 9a). Although Wall et al. (2011) suggested that an observed increase in hole number with time may reflect an increase in population size of the excavator, the significant increase in number of holes observed at the 'Yongala' may equally be explained by a shift in location (radially away from the wreck) rather than by increased intensity of activity.

Overall, the temporal variability of the distribution of holes indicates that a halo is a long-lived but not a static structure, and that excavation activity is ongo-

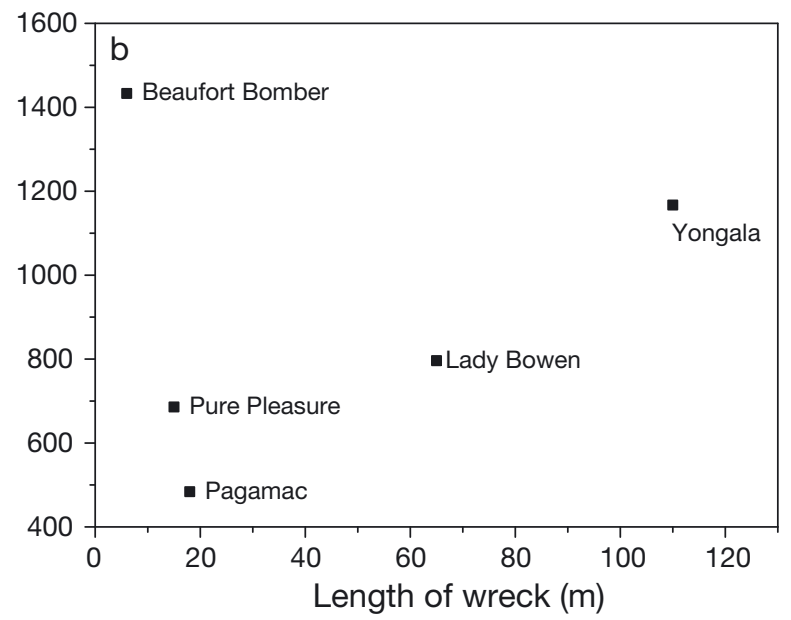

Fig. 9. Number of holes at each wreck versus (a) age and (b) length of the wreck, respectively 
ing on decadal time scales. The relationship between halo size and wreck age indicates that holes outlive their creator, which is considered an important characteristic of ecosystem engineering activity (Hastings et al. 2007).

\section{Potential ecological role of the wreck}

The halo-like distribution of the holes around the wreck, with their mean location within a few tens of meters from the wreck, clearly indicates that the wreck provides a nucleus for halo formation. A priori, there are 3 potential roles of the wreck: (1) the wreck is a habitat for the bioturbator, who ventures to the seafloor from this central place; (2) the wreck itself is not inhabited by the bioturbator, and instead is used as a navigation marker for animals that live on the 'open' seafloor; or (3) infaunal productivity is increased close to the wreck, which results in increased grazing by benthic feeders close to the wreck (e.g. Kurz 1995).

It is reasonable to assume that the number of holes excavated over time at any given site is related to some degree with the number of animals excavating (cf. Scanlon et al. 2005), if all other processes (notably hole infilling by sediment transport) remain the same. If the wreck provides a habitat for the bioturbator (case 1 above), a priori, a larger wreck should provide habitat for a more numerous population, and thus larger wrecks should have a larger halo (in terms of number of holes). The large number of holes found at the smallest wreck, i.e. that of the 'Beaufort Bomber' plane, clearly indicates that the halo size does not reflect the size of the wreck (Fig. 9b). Unless burrowing activity per individual bioturbator is significantly greater there than at other sites, the number of animals excavating would have to be similar in order to create a similar 'turnover' rate to that observed at the 'Yongala' and 'Lady Bowen.' It is thus suggested that the wreck is not a habitat for the bioturbator (case 1), and perhaps more likely a navigation 'beacon' for animals that inhabit the softsediment seafloor environments (case 2).

The circular shape of the halo with a 'blank' area in the center, together with the apparent expansion in halo diameter over time, is consistent with the depletion of a resource by a central forager: a forager who orients its feeding strategy on the center point of the wreck (but does not necessarily inhabit the center point) will initially forage close to the wreck, and move farther away as resources deplete (e.g. Rosenberg \& McKelvey 1999). The shape of the halo may thus be a result of current and past prey distribution. However, Schneider (1992) pointed out that if predator behavior is dictated by prey density, then over time, spatial variance of prey increases, and conversely if dictated by predator density, then spatial variance of prey density decreases (Schneider 1992, Thrush 1999). If the hole pattern indeed reflects a feeding behavior, the highly ordered distribution suggests that halo shape more likely reflects predator behavior than prey distribution (or resource availability).

\section{Benthic habitat engineering}

The halos provide a habitat for epibenthic assemblages that are absent elsewhere on the adjacent flat seafloor (Fig. 8). The results of this study thus further support the recognized importance of small-scale habitat diversity and structure (Murray et al. 2002, Hewitt et al. 2005), and the argument renewed by Kristensen et al. (2012) and Meadows et al. (2012) that bioturbation must be considered an important habitat engineering process.

A similar differentiation of habitats associated with holes has previously been observed in at least 2 settings. Whereas pockmarks (holes of usually abiotic origin) in a Norwegian Fjord were found to influence abundance but not composition of benthic species (Webb et al. 2009), in the grouper holes in the Gulf of Mexico, similarly diverse assemblages of hardsubstrate-associated species were found that are not present on the adjacent seafloor (Coleman et al. 2010). Wildish et al. (2008) also reported specialized benthic communities associated with pockmark habitats of unknown origin in Canada's Bay of Fundy. A simple colonization sequence, occurring on decadal time scales, can explain the observed distribution of biota in the halos around wrecks (Stieglitz 2012). During initial creation of a shallow hole at the outer edge of a halo and subsequent ongoing excavation to a deep hole, a hole remains bare and uncolonized by either floral or faunal assemblages (Figs. 7 \& $8)$, analogous to disruption of growth in seagrass beds due to bioturbation (Townsend \& Fonseca 1998). With time, rubble transported on the flat seafloor by bottom currents accumulates inside holes and may be consolidated by encrusting algae, eventually reducing or preventing further bioturbation of soft sediment. The (consolidated) rubble provides a hard substrate for the development of isolates and species-rich gardens in such 'older' holes. A similar reason for observed sessile species diversity in 
grouper holes was suggested by Scanlon et al. (2005) and Coleman et al. (2010). Cessation of excavation, sediment infilling, and rim erosion reduce hole depth over time. Colonized holes thus appear to represent an older, no-longer excavated section of the halo. It is interesting to note that some of the observed epibenthos (sponges, corals) is estimated to be of an age of up to $20 \mathrm{yr}$ or more (C. Battershill pers. comm.), consistent with the observed temporal variability of holes. Outside the halos, the growth of marine plants indicates that the seafloor morphology is not significantly disturbed, at least on the time scale of the plant growth (cf. Townsend \& Fonseca 1998). The chosen classification scheme thus effectively represents a temporal sequence in seabed colonization following bioturbation (plants $\rightarrow$ bare $\rightarrow$ rubble $\rightarrow$ isolate $\rightarrow$ garden).

In summary, the results of this study indicate the potential for large artificial reefs such as wrecks to significantly impact the surrounding seafloor. Systematic disturbance of the seabed around the wrecks occurs on timescales of decades, and provides a habitat for benthic assemblages that are distinctly different from the benthic communities on the surrounding undisturbed seafloor. The (to date unidentified) animal(s) responsible for the excavations are thus allogenic ecosystem engineers, transforming softsediment habitats by their activity (Jones et al. 1994). The systematic occurrence of the substantial halos around wrecks suggests that 'the ecosystem wreck' extends beyond the spatial confines of the hull of a wreck to the seafloor, by a distance an order of magnitude greater than the size of the wreck itself. As the interest in using and deploying artificial reefs increases for management or harvesting of marine resources, it is important to understand their potential impact on the seabed. Whether an artificial reef is installed intentionally as fish habitat, unintentionally as a shipwreck, or for other purposes, e.g. offshore wind farms, this study indicates that changes to seabed morphology and sessile assemblages surrounding the structures may be expected to occur on decadal timescales, and that they may be independent from the size of the structure.

Acknowledgements. Multibeam data were collected with a pole-mounted echosounder on RVs 'James Kirby' and 'Lady Basten,' funded by the Australian Institute of Marine Science (AIMS) and the Cooperative Research Centre for Coastal, Estuarine and Waterways Management. Image data were collected from the AIMS vessel RV 'Cape Ferguson.' The efforts of the vessel crews are greatly appreciated. Data were processed with the software SWATHED developed by J. Hughes Clarke, University of New Brunswick (Canada), and with IVS Fledermaus and Quantum GIS. G.
Coombes, E. Eriksson, G. Suosaari, R. Schroeder, and J. Clancy provided field support with data collection and many thoughts on the holes. Thanks to P. Doherty, S. Kininmonth, R. Jones, L. Zell, M. Cappo, I. Banks, A. Viduka, P. Crocombe, R. Fitzpatrick, and others for offering thoughts on the processes occurring at the wrecks. I thank S. Kininmonth for an initial statistical analysis of the hole pattern and for teaching me GIS tools. The positive and constructive comments of 3 reviewers are greatly appreciated. I currently hold an International Incoming Fellowship funded by the European Union Marie Curie Program, and am visiting the Centre National de La Recherche Scientifique (CNRS) and the University of Western Brittany. This is a contribution from the Nereis Park-The Bioturbation World (www. nereispark.org).

\section{LITERATURE CITED}

Able KW, Twichell DC, Grimes CB, Jones RS (1987) Tilefishes of the genus Caulolatilus construct burrows in the sea floor. Bull Mar Sci 40:1-10

Cappo M, Kelley R (2001) Connectivity in the Great Barrier Reef World Heritage Area - an overview of pathways and processes. In: Wolanski E (ed) Oceanographic processes of coral reefs: physical and biological links in the Great Barrier Reef. CRC Press, Boca Raton, FL, p 161-167

Cappo M, Stowar M, Stieglitz T, Lawrey E, Johansson C, MacNeil A (2012) Measuring and communicating effects of MPAs on deep 'shoal' fisheries. Proc 12th Int Coral Reef Symp. Available at www.icrs2012.com/proceedings/ manuscripts/ICRS2012_18A_1.pdf

Coleman FC, Koenig CC, Scanlon KM, Heppell S, Heppell S, Miller MW (2010) Benthic habitat modification through excavation by red grouper, Epinephelus morio, in the northeastern Gulf of Mexico. Open Fish Sci J 3:1-15

> Coleman JM, Garrison LE (1977) Geological aspects of marine slope stability, northwestern Gulf of Mexico. Mar Georesour Geotechnol 2:9-44

Fonseca MS, Kenworthy WJ, Griffith E, Hall MO, Finkbeiner M, Belle SS (2008) Factors influencing landscape pattern of the seagrass Halophila decipiens in an oceanic setting. Estuar Coast Shelf Sci 76:163-174

Fricke HW (1980) Mating systems, maternal and biparental care in triggerfish (Balistidae). Z Tierpsychol 53:105-122

Hastings A, Byers JE, Crooks JA, Cuddington K and others (2007) Ecosystem engineering in space and time. Ecol Lett 10:153-164

Hewitt JE, Thrush SE, Halliday J, Duffy C (2005) The importance of small-scale habitat structure for maintaining beta diversity. Ecology 86:1619-1626

Hines AH, Whitlatch RB, Thrush SF, Hewitt JE, Cummings VJ, Dayton PK, Legendre P (1997) Nonlinear foraging response of a large marine predator to benthic prey: eagle ray pits and bivalves in a New Zealand sandflat. J Exp Mar Biol Ecol 216:191-210

Hovland M, Judd A (1988) Seabed pockmarks and seepages: impact on geology, biology, and the marine environment. Graham \& Trotman, London

IMOS (Integrated Marine Observing System) (2010) Integrated Marine Observing System National Reference Station (NRS) Yongala Mooring. Available at http://imos. org.au/emii_data.html (accessed July 2012)

Jones CG, Lawton JH, Shackak M (1994) Organisms as ecosystem engineers. Oikos 69:373-386 
Kristensen E, Penha-Lopes G, Delefosse M, Valdemarsen T, Quintana CO, Banta GT (2012) What is bioturbation? The need for a precise definition for fauna in aquatic sciences. Mar Ecol Prog Ser 446:285-302

Kurz RC (1995) Predator-prey interactions between gray triggerfish (Balistes capriscus Gmelin) and a guild of sand dollars around artificial reefs in the northeastern Gulf of Mexico. Bull Mar Sci 56:150-160

Kvitek RG, Oliver JS (1986) Side-scan sonar estimates of the utilization of gray whale grounds along Vancouver Island, Canada. Cont Shelf Res 6:639-654

Malcolm HA, Cheal AJ, Thompson AA (1999) Fishes of the Yongala historic shipwreck. Tech Rep 26. CRC Reef Research Centre, Townsville. Available at www.reef.crc. org.au/publications/techreport/TechRep26.html

Meadows PS, Meadows A, Murray JMH (2012) Biological modifiers of marine benthic seascapes: their role as ecosystem engineers. Geomorphology 157-158:31-48

Murray JMH, Meadows A, Meadows PS (2002) Biogeomorphological implications of microscale interactions between sediment geotechnics and marine benthos: a review. Geomorphology 47:15-30

Orpin AR, Ridd PV, Stewart LK (1999) Assessment of the relative importance of major sediment transport mechanisms in the central Great Barrier Reef lagoon. Aust J Earth Sci 46:883-896

Pitcher CR, Venables W, Ellis N, McLeod I and others (2002) Great Barrier Reef Seabed Biodiversity Mapping Project: Phase 1, Report to CRC Reef. Available at www.reef.crc. org.au/resprogram/programC/seabed/Title\&Summary. pdf

Rosenberg DK, McKelvey KS (1999) Estimation of habitat

Editorial responsibility: Martin Solan,

Southampton, UK selection for central-place foraging animals. J Wildl Manag 63:1028-1038

Scanlon KM, Coleman FC, Koenig CC (2005) Pockmarks on the outer shelf in the northern Gulf of Mexico: gasrelease features or habitat modifications by fish? Am Fish Soc Symp 41:301-312

Schneider DC (1992) Thinning and clearing of prey by predators. Am Nat 139:148-160

Stieglitz TC (2012) The Yongala's halo of holes - systematic bioturbation close to a shipwreck. In: Harris PT, Baker EK (eds) Seafloor geomorphology as benthic habitat: GeoHab Atlas of seafloor geomorphic features and benthic habitats. Elsevier, London, p 277-287

Thrush SF (1999) Complex role of predators in structuring soft-sediment macrobenthic communities: implications of changes in spatial scale for experimental studies. Aust J Ecol 24:344-354

- Townsend EC, Fonseca MS (1998) Bioturbation as a potential mechanism influencing spatial heterogeneity of North Carolina seagrass beds. Mar Ecol Prog Ser 169: 123-132

- Wall CC, Donahue BT, Naar DF, Mann DA (2011) Spatial and temporal variability of red grouper holes within Steamboat Lumps Marine Reserve, Gulf of Mexico. Mar Ecol Prog Ser 431:243-254

Webb KE, Barnes DKA, Gray JS (2009) Benthic ecology of pockmarks in the Inner Oslofjord, Norway. Mar Ecol Prog Ser 387:15-25

Wildish DJ, Akagi HM, McKeown DL, Pohle GW (2008) Pockmarks influence benthic communities in Passamaquoddy Bay, Bay of Fundy, Canada. Mar Ecol Prog Ser 357:51-66

Submitted: August 23, 2012; Accepted: November 8, 2012 Proofs received from author(s): February 17, 2013 